\title{
Herbal medicine use among patients with viral and non-viral Hepatitis in Uganda: prevalence, patterns and related factors
}

\author{
Sara Nsibirwa ${ }^{1 *}$ (D), Godwin Anguzu1', Sam Kamukama², Ponsiano Ocama ${ }^{1}$ and Joan Nankya-Mutyoba²
}

\begin{abstract}
Background: There is some evidence that patients with liver diseases commonly use complementary and alternative therapies to address general and liver-disease specific health concerns. The purpose of this study was to assess and describe prevalence, patterns and related factors of herbal medicine use among adults diagnosed with viral and non-viral hepatitis in Kampala, Uganda.

Methods: A cross-sectional study was conducted on 310 adult patients attending the gastrointestinal clinic in Mulago hospital referral hospital in Kampala. Data on prevalence, types and reasons for herbal medicine use was collected using standardized questionnaires and focus group discussions. Modified Poisson regression analyses were used to examine factors related to use.

Results: Usage of various herbal remedies within 12 months prior to April 2018 was reported by $46.1 \%$ (143/310) of patients with 27.3\% (39/143) of these reporting having used conventional and herbal therapies concurrently. Herbal remedies were used to treat various health conditions including hepatitis. Patients with hepatitis $C$ virus infection ( $P R R=1.16, p=0.02)$ compared to those with hepatitis $B$ virus infection, and those who believed that it was safe to use herbal and conventional therapies concurrently (PRR $=1.23, p=0.008$ ) had higher prevalence odds of herbal medicine use. Conversely, patients who had been newly diagnosed with hepatitis (PRR $=0.69, p=0.03$ ) compared to those who had been diagnosed more than one-year prior, had lower prevalence odds of herbal medicine use. Various types of local herbs were reported as most commonly used however most patients did not know the ingredients of commercially prepared herbal therapies.

Conclusion: A high prevalence of herbal medicine use was found among newly-diagnosed patients and patients with hepatitis $\mathrm{C}$ more likely to use herbal remedies after adjusting for other factors. Usage was influenced by the belief that herbal medicine is safe and effective. Health workers need to consistently elicit information about herbal remedy use. Research is needed on benefits, adverse effects and outcomes in patients who use herbal remedies to treat primary liver diseases in order to facilitate evidence of efficacy and product safety.
\end{abstract}

Keywords: Complementary and alternative medicine, Hepatitis B, Hepatitis C, Herbal medicine

\footnotetext{
* Correspondence: snsibirwa@yahoo.com

${ }^{1}$ Infectious Disease Institute, College of Health Sciences, Makerere University, Kampala, Uganda

Full list of author information is available at the end of the article
}

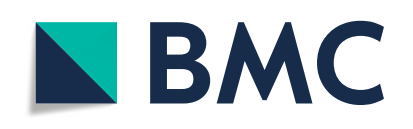

(- The Author(s). 2020 Open Access This article is licensed under a Creative Commons Attribution 4.0 International License, which permits use, sharing, adaptation, distribution and reproduction in any medium or format, as long as you give appropriate credit to the original author(s) and the source, provide a link to the Creative Commons licence, and indicate if changes were made. The images or other third party material in this article are included in the article's Creative Commons licence, unless indicated otherwise in a credit line to the material. If material is not included in the article's Creative Commons licence and your intended use is not permitted by statutory regulation or exceeds the permitted use, you will need to obtain permission directly from the copyright holder. To view a copy of this licence, visit http://creativecommons.org/licenses/by/4.0/. The Creative Commons Public Domain Dedication waiver (http://creativecommons.org/publicdomain/zero/1.0/) applies to the data made available in this article, unless otherwise stated in a credit line to the data. 


\section{Background}

Hepatitis viruses are the most common cause of hepatitis in the world but other infections, substances such as alcohol and drugs, and autoimmune diseases can also cause hepatitis.

Hepatitis B virus (HBV) infection causes significant global burden of disease with 257 million chronically infected [1]. Hepatitis $\mathrm{C}$ virus ( $\mathrm{HCV}$ ) infection also poses a significant disease burden globally with an estimated 71 million people reported to have chronic infection [2]. Both infections account for 1.3 million deaths of mortality from cirrhosis and liver cancer per year [3] despite availability of treatment. In Uganda, the most commonly diagnosed forms of hepatitis are caused by HBV with a prevalence ranging from 10 to $25 \%$ [4] and alcohol liver disease reported in $10 \%$ of the population [5].

As in many other places globally, it has been observed that conventional medical care co-exists with traditional medical care systems in Uganda. Patients may use medicine from one system exclusively or they may acquire medicine from each health system and use it simultaneously or sequentially hence the medical pluralism noted among patients [6]. Due to the high costs of treatment for $\mathrm{HCV}$, the long-term treatment required for $\mathrm{HBV}$ infection and treatment-associated adverse effects, limited treatment options for drug-induced liver inflammation(DILI) and alcoholic hepatitis, many patients choose either to supplement antiviral medications with herbal products or to reject conventional therapy altogether and instead rely solely on herbal medicine as an alternative form of therapy $[7,8]$.

Patients with chronic liver disease have been found to use non-conventional therapies frequently $[9,10]$ with surveys done in the USA suggesting that the frequency of herbal medicine use among patients with chronic liver disease ranges between 40 and 50\% [8]. High rates of herbal use have been found in other populations of patients with liver diseases [11], including only patients with hepatitis $\mathrm{C}$ or hepatitis $\mathrm{B}$, or drawing patients from a single institution [12, 13]. Although users of herbal medicines believe they are safer, evidence of toxicity to the liver from using herbal remedies has been documented [14, 15].

There is limited data on herbal medicine use among populations affected by viral and non-viral hepatitis in sub-Saharan Africa. Although several studies have described herbal medicine use in USA [16, 17], in Uganda, few have studied use among a population with preexisting liver disease. Most studies on herbal use in Uganda and other sub-Saharan countries have focused on populations with HIV and diabetes and there is a paucity of literature on the prevalence and rationale of herbal medicine use among patients with liver disease in sub-Saharan Africa. Specific research to quantify and describe the extent of use among patients with liver diseases is still lacking and little is known about the use of herbal medicine among patients who have been diagnosed with hepatitis in Uganda. A study in rural Rakai examined the relationship between herbal medicine use and liver disease and found an association with liver fibrosis [18]. There is a lack of information on prevalence, patterns and reasons for use, and whether users are aware of possible side effects and complications. This study therefore sought to determine the prevalence of herbal medicine use, explore types of herbal medicines used, reasons for use and determine the factors associated with use among adults with viral and non-viral hepatitis.

\section{Methods \\ Study design and setting}

The study was conducted within the gastroenterology clinic of Mulago hospital, a tertiary teaching and National Referral Hospital, in Kampala; which handles up to 100 adult patients weekly on average; with either luminal gastrointestinal issues or liver/pancreatic conditions. The study specifically targeted patients who had a known diagnosis of liver inflammation due to different causes such as hepatitis B virus, hepatitis $C$ virus, druginduced and alcohol-induced inflammation as shown on their medical records. Data was collected using standardized questionnaires followed by focus group discussions (FGDs) on a sample of patients. The questionnaires used were modified from the International Questionnaire to Measure Use of Complementary and Alternative Medicine (ICAM-Q) [19];.

\section{Sample selection}

The sample size was calculated based using the LeslieKish formula below;

$n=\frac{z^{2} p q}{e^{2}}$ at a $95 \%$ confidence level, with an estimated proportion of herbal medicine use among patients with hepatitis of $23 \%$ based on a previous study [20], and $5 \%$ precision rate. After adjusting for a non-response rate of $10 \%$, a total sample size of 310 patients was determined and recruited using systematic sampling.

To get the full sample size, approximately 30 patients were interviewed weekly between April and June 2018. To get the sampling interval, 80, which is the average number of hepatitis patients seen weekly was divided by the required number of patients weekly [21] to get an interval of two, therefore every other individual on the $\log$ of patients attending the clinic was approached for recruitment. The starting number on the patient log was chosen randomly each week to ensure that all potential patients had an equal chance of selection. Four FGDs, homogenous by gender and purposively sampled, were 
conducted. Eligibility criteria included consenting adults aged 18 years and above who were diagnosed with either hepatitis $\mathrm{B}$, hepatitis $\mathrm{C}$, alcoholic hepatitis or druginduced hepatitis. Patients with impaired mental capacity to provide coherent and reliable information were excluded from participating in the study.

\section{Data collection}

Research assistants were trained to administer structured questionnaires. Data collected included socio-demographic factors (age, gender, ethnicity, religion, education level, employment status, type of occupation, residence); use of herbal medicine (ever used, duration of use, use within the last 12 months), the forms, mode of administration and frequency of use of herbal medicine, timing (timing with respect to the diagnosis of hepatitis-categorized as before or after, timing with respect to how often it was used, timing with respect to concurrent use of herbal medicine with conventional medicine) source (the source of the herbal medicine and the source of information about the herbal medicine), clinical factors (duration of illness, diagnosis, type of treatment, duration of treatment) and other factors expected to influence use of herbal medicine (accessibility, perceived benefits from herbal medicine and perceived side effects from herbal medicine). (See survey questionnaire in Additional file 1 attached).

In addition to collecting survey data, the investigators collected data via focus groups. Following each interviews, the research assistants asked for volunteers to participate in focus group discussions to identify how groups of patients think about behaviors and practices linked to herbal medicine use, to explore the reasons for the use of herbal medicine and to examine the social, cultural and economic factors associated with the use of herbal medicine.

Four FGDs were held; two with female patients and two with male patients. Each group was comprising 7-9 patients, homogenous by sex and not widely variable by age. An FGD guide was used to moderate the discussions on the reasons for the use of herbal medicine [22].

\section{Definitions}

The use of herbal medicine was investigated at three levels: ever used, use within 12 months prior to April 2018 and use at the time of the study. Patients who had used herbal medicine at least once in the period of 12 months before April 2018 were classified as herbal medicine users; those who had used herbal medicine at least once in their lifetime but not during the previous 12 months were classified as herbal medicine exposed while those who reported never having used it in their lifetime were classified as non-users.

\section{Statistical analysis}

Data was analyzed using STATA 13.0 (StataCorp. 2013. Statistical Software: Release 13. College Station, TX: StataCorp LP.). Modified Poisson regression analyses [23] were done to determine the factors associated with the use of herbal medicine. Prevalence rate ratios, with 95\% confidence interval $(\mathrm{CI})$ were examined to determine the strength of association.

\section{Analysis of qualitative data}

Data from discussions was analyzed immediately following collection. Conclusions were made using thematic analysis.

\section{Results}

The background characteristics of the patients are presented in Table 1 while the characteristics of the patients in the FGDs are presented in supplementary table 1; Additional file 2 . The study had 310 patients with a median age of 30 (IQR $\left.{ }^{1} 17-73\right)$. Majority were aged 25-34 years, male, and residing in urban areas. Most patients were either Catholic (41.6\%) or Protestants (38.1\%) by religion and had attained secondary level of education as their highest level of education. Over $60 \%$ reported being currently employed at the time of the interview, with the larger proportion employed in the informal sector.

Over $90 \%$ of the patients were diagnosed with hepatitis $\mathrm{B}$ and majority of the patients had been diagnosed less than 6 months before participating in the study. Fortyeight percent of the patients were not on any form of treatment for their liver disease while of those who were on treatment, about $72 \%$ had been on treatment for less than 6 months.

\section{Prevalence of herbal medicine use}

The use of herbal medicine was investigated at three levels: ever used during lifetime, use within the last 12 months and use at the time of the study.

Lifetime exposure to herbal medicine was reported in $174 / 310(56.1 \%)$ patients while herbal medicine use within the last 12 months was reported by $143 / 310$ (46.1\%) patients.

About 11.9\% (37/310) of the patients were reportedly using herbal medicine at the time of the study.

The patients who reported "never used" of herbal medicine were asked to give reasons for never having used it. The main reasons given by patients for non-use of herbal medicine included: lack of trust in the effectiveness of herbal medicine generally (22.8\%), lack of knowledge about herbal medicine (16.2\%), a lack of interest in using herbal medicine (16.2\%), bad taste of

\footnotetext{
${ }^{1} \mathrm{IQR}$ - Interquartile range
} 
Table 1 Baseline characteristics of 310 individuals diagnosed with hepatitis attending the gastroenterology clinic in Mulago National Referral Hospital between April and June 2018

\begin{tabular}{|c|c|c|c|}
\hline Variable & Variable & Frequency $(N=310)$ & Percentage (\%) \\
\hline \multirow[t]{5}{*}{ Age groups } & $18-24$ & 77 & 24.8 \\
\hline & $25-34$ & 100 & 32.3 \\
\hline & $35-44$ & 74 & 23.9 \\
\hline & $45-54$ & 47 & 15.2 \\
\hline & $\geq 55$ & 12 & 3.9 \\
\hline \multirow[t]{2}{*}{ Gender } & Male & 171 & 55.2 \\
\hline & Female & 139 & 44.8 \\
\hline \multirow[t]{2}{*}{ Area of residence } & Rural & 59 & 19.0 \\
\hline & Urban & 251 & 81.0 \\
\hline \multirow[t]{5}{*}{ Region of origin } & Foreign & 16 & 5.2 \\
\hline & Central & 129 & 41.6 \\
\hline & Western & 59 & 19.0 \\
\hline & Northern & 46 & 14.8 \\
\hline & Eastern & 60 & 19.4 \\
\hline \multirow[t]{4}{*}{ Religion } & Protestant & 118 & 38.1 \\
\hline & Roman Catholic & 129 & 41.6 \\
\hline & Islam & 30 & 9.7 \\
\hline & Others $^{a}$ & 33 & 10.6 \\
\hline \multirow[t]{4}{*}{ Education status } & Not educated & 4 & 1.3 \\
\hline & Primary & 90 & 29.0 \\
\hline & Secondary & 145 & 46.8 \\
\hline & Post-secondary ${ }^{\mathrm{b}}$ & 71 & 22.9 \\
\hline \multirow[t]{2}{*}{ Current employment } & No & 123 & 39.7 \\
\hline & Yes & 187 & 60.3 \\
\hline \multirow[t]{3}{*}{ Type of occupation } & Formal & 60 & 19.4 \\
\hline & Informal & 148 & 47.7 \\
\hline & Not employed & 102 & 32.9 \\
\hline \multirow[t]{5}{*}{ Current diagnosis } & $\mathrm{HBV}^{\mathrm{c}}$ & 289 & 93.2 \\
\hline & $\mathrm{HCV}^{\mathrm{d}}$ & 12 & 3.9 \\
\hline & $\mathrm{HBV} \& \mathrm{HCV}$ & 4 & 1.3 \\
\hline & Drug-induced & 3 & 1.0 \\
\hline & Alcoholic hepatitis & 2 & 0.6 \\
\hline \multirow[t]{4}{*}{ Duration of illness } & Less than 6 months & 169 & 54.5 \\
\hline & 6-12 months & 67 & 21.6 \\
\hline & 13-24 months & 34 & 11.0 \\
\hline & $>24$ months & 40 & 12.9 \\
\hline \multirow[t]{2}{*}{ On treatment for hepatitis } & No & 148 & 47.7 \\
\hline & Yes & 162 & 52.3 \\
\hline \multirow[t]{4}{*}{ Kind of treatment } & Conventional only & 150 & 48.4 \\
\hline & Herbal only & 4 & 1.3 \\
\hline & Conventional\&Herbal & 8 & 2.6 \\
\hline & Not on treatment & 148 & 47.7 \\
\hline Duration of treatment & Less than 1 month & 37 & 11.9 \\
\hline
\end{tabular}


Table 1 Baseline characteristics of 310 individuals diagnosed with hepatitis attending the gastroenterology clinic in Mulago National Referral Hospital between April and June 2018 (Continued)

\begin{tabular}{llll}
\hline Variable & Variable & Frequency $(N=310)$ & Percentage $(\%)$ \\
\hline & $1-6$ months & 79 & 25.5 \\
& $7-12$ months & 24 & 7.7 \\
& $13-24$ months & 16 & 5.2 \\
& $>24$ months & 6 & 1.9 \\
& Not applicable & 148 & 47.7 \\
\hline
\end{tabular}

${ }^{a}$ Others included members of the Pentecostal, Seventh-Day Adventists and Jehovah Witness faiths

bost-secondary included both tertiary and vocational levels

'HBV- Hepatitis B virus

${ }^{d}$ HCV-Hepatitis $C$ virus

herbal medicine (10.3\%), easier access to hospitals (8.1\%) and lack of trust in the safety of herbal medicines (5.9\%).

\section{Reasons for the use of herbal medicine}

The main reasons given for use of herbal medicine in the group discussions were related to convenience, availability, cost, cultural norms and aggressive marketing strategies used by herbal medicine retailers. All these were seen to increase accessibility for the population to herbal medicine therefore leading to increased utilization.

One of the main reasons given as to why herbal medicine was used despite the availability of conventional treatment was the easy accessibility and availability of herbal therapies and herbal practitioners compared to conventional health facilities.

"...Those who sell herbal medicine are everywhere, they even come to one's door, even in the market. At least one does not get disappointed as it is in the hospital where one is told that the doctor has not yet come, yet one has come from afar and then has to wait the whole day. It is easier to find a herbalist nearby so I can get back home quickly..." (Male, FGD 1).

Several patients also noted that the cheaper cost of herbal therapies as a reason for use of herbal medicine in the group discussions however they concluded that whereas the cost of herbal treatment for simple ailments such as cough and malaria is cheap, herbal concoctions used to treat chronic diseases such as hepatitis end up being expensive due to the long-term use.

Another reason given for use of herbal medicine was that herbal medicine has been used for many years and is a part of the culture hence the reason for its use especially for conditions such as pregnancy. Many of the patients expressed dismay that health workers have a negative attitude towards herbal medicine despite the fact that the knowledge of herbal medicine has been passed down from past generations.

“...Our ancestors used these herbs without getting any problems, all the women in the past used herbs to give birth properly. How come they did not get liver diseases? They knew what was dangerous and they taught it to their children. Even now, we know which herbs are dangerous and which ones are useful. However, you see these doctors tell us that we should not use any herbs. That is not good, because it is a part of our culture and has helped our people for many years. If herbs were bad, then all our people would have died by now..." (Female, FGD 3).

\section{Indications of herbal medicine use}

Among patients who used herbal medicine within the last 12 months, $34 / 143(23.8 \%)$ were using it to treat hepatitis while 109/143 (76.9\%) were using it for various health conditions which are shown in Fig. 1.

This was also confirmed in all the focus groups sessions where patients reported that either they or other patients they knew who had been diagnosed with hepatitis used herbal medicines, not only to treat conditions of the liver but a range of other medical conditions. Twenty-six percent (37/143) reported using herbal medicine for treatment of respiratory conditions such as cough, asthma and the common cold, 33/143 (23.1\%) for gastrointestinal conditions including abdominal pain, abdominal discomfort and diarrhea, 25/143(17.5\%) for malaria, $16 / 143(11.2 \%)$ for antenatal care and 6/ 143(4.2\%) for fever.

Other indications reported included sexually transmitted infections (7.7\%), skin diseases (2.8\%) non-communicable diseases(NCDs) such as diabetes and hypertension (2.1\%), joint and bone health (3.5\%), gynecological conditions such as infertility, post abortion care (5.6\%) and erectile dysfunction (1.4\%). Conditions such as allergies, epilepsy, general body weakness, kidney stones and alcohol dependence which were reported by only a few patients were reported under other indications on Fig. 1.

\section{Profile and patterns of herbal medicine use}

The most commonly used herbal therapies have been described in Table 2. The majority of the patients reported that while they did know the types of herbal medicines which they picked themselves or get from friends or family members, they did not know which 


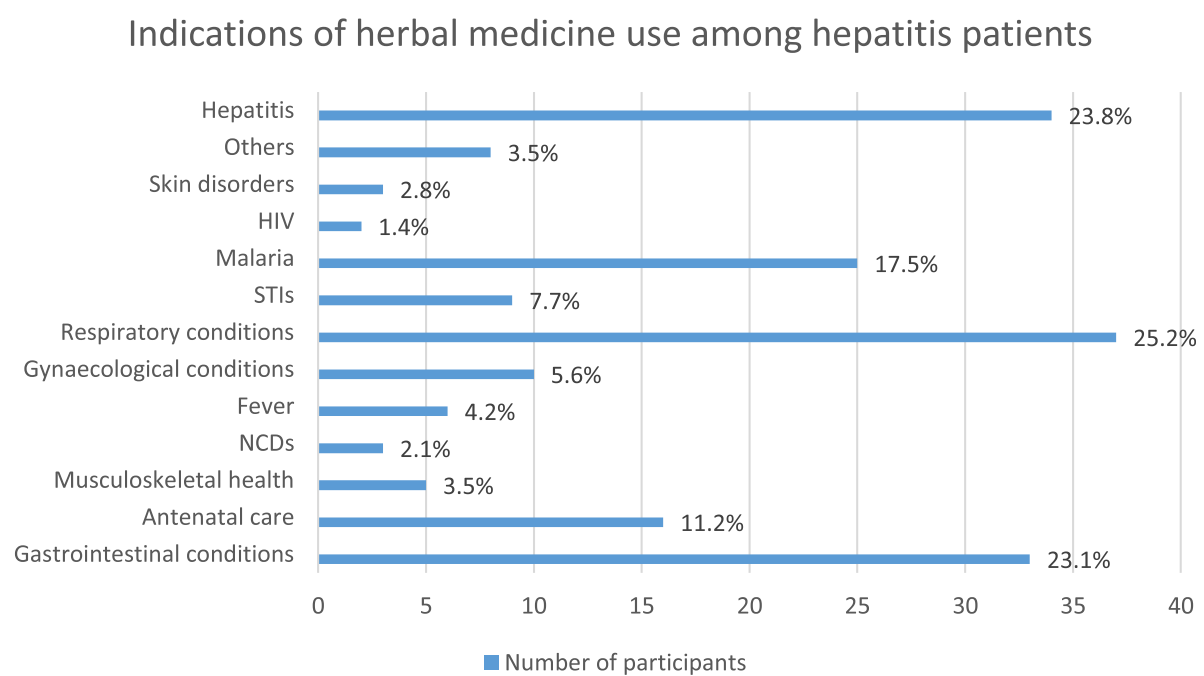

Fig. 1 Indications of herbal medicine use among hepatitis patients. The 143 patients who reported use of herbal medicine were asked what conditions they were treating with the herbal medicine. The different bars indicate the frequency of reporting of an indication of use of herbal medicine. However, some patients were using herbal medicine for more than one indication and had multiple responses. Common respiratory conditions were the most frequently reported indications followed by hepatitis and other gastrointestinal conditions. HIV-Human

Immunodeficiency Virus; NCDs- Non-Communicable Diseases

exact herbs are part of the herbal preparations obtained from herbalists and herbal medicine retailers.

Majority of the patients reported using a liquid form of herbal medicine, with 100/143(69.9\%) patients reporting oral administration in form of teas or juices. Herbal medicine retailers and herbalists were reported as the more common sources of herbal medicine with each having 55/143(38.5\%) of herbal medicine users reporting them as their sources, $30 / 143(21 \%)$ obtained the herbal medicine from friends and family members, and 18/143

Table 2 Commonly used herbs by patients diagnosed with viral and non-viral hepatitis in Kampala, Uganda

\begin{tabular}{|c|c|c|c|}
\hline $\begin{array}{l}\text { Local name of } \\
\text { herb }\end{array}$ & Scientific name & Indication & Preparation \\
\hline Kigagyi & Aloe vera & Fever, skin infections, wounds & $\begin{array}{l}\text { Boiled and drank as tea/juice, raw sap } \\
\text { applied to skin }\end{array}$ \\
\hline Ebombo & $\begin{array}{l}\text { Memodica } \\
\text { feotida }\end{array}$ & Body odour & Ground and applied to body as paste \\
\hline Kamunye & $\begin{array}{l}\text { Hoslundia } \\
\text { opposita }\end{array}$ & Wounds, skin infections & Crushed leaves applied directly \\
\hline Mubiri & - & Anorexia, for weight gain & Juice drank orally \\
\hline Enjaga & Cannabis sativa & Pain relief, antidepressant & Juice drank \\
\hline Ekiyondo & $\begin{array}{l}\text { Kalanchoe } \\
\text { glaucescens }\end{array}$ & Nasal congestion, common cold & Crushed and drunk as tea, nasal drops \\
\hline Mululuza & $\begin{array}{l}\text { Vernonia } \\
\text { Amygdalina }\end{array}$ & Fever, Malaria & Leaves boiled for drinking as tea \\
\hline Emumbwa & Clay soil & $\begin{array}{l}\text { Pregnancy, STIs, Joint aches, abdominal discomfort, Erectile } \\
\text { dysfunction, to induce ovulation }\end{array}$ & $\begin{array}{l}\text { Ground in water and drunk } \\
\text { Pastes smeared on body }\end{array}$ \\
\hline Ekifumufumu & $\begin{array}{l}\text { Leonotis } \\
\text { nepetifolia }\end{array}$ & Menorrhagia, abdominal pain, muscle aches & Leaves boiled for drinking, smeared \\
\hline Ssere & Bidens pilosa & Goitre, wounds & $\begin{array}{l}\text { Leaves crushed and juice applied to } \\
\text { wounds }\end{array}$ \\
\hline Muyembe & Mangifera indica & Cough & Leaves boiled and drunk as tea \\
\hline Musaayi & $\begin{array}{l}\text { Hibiscus } \\
\text { acetosella }\end{array}$ & Anemia & Crushed and boiled for drinking \\
\hline Entangawuzi & Zingber officinale & Cough, flu & Chewed whole or boiled in tea \\
\hline
\end{tabular}


(12.6\%) reporting that they picked the herbal medicine themselves.

The largest proportion of herbal medicine users 109/ 143 (76.2\%); were influenced to do so by family members to use herbal medicine. This was followed by media: television, radio and newspaper advertisements, which influenced 75/143 (52.5\%). The patients' other sources of information about herbal medicine included their friends 34/143 (23.8\%); herbal practitioners 13/143 (9.1\%); and community elders 8/143 (5.6\%).

\section{Period of time of herbal medicine use}

With regards to the period of use, 97/143(67.8\%) of herbal medicine users reported that they were using herbal medicine prior to being diagnosed with any form of hepatitis; 91/143(63.6\%) reported that they started using herbal medicine after they had been diagnosed with any form of hepatitis; $37.4 \%$ of these (34/91) started using the herbal therapies for the treatment of hepatitis with slightly over half (19/34) of these starting treatment within a period of 1 week following diagnosis.

None of the patients reported initiation of herbal therapies for hepatitis treatment more than 6 months after diagnosis.

\section{Concurrent use of herbal medicine with conventional prescription treatment}

Same-day use of both herbal and conventional treatment was reported by 39/143(27.3\%). Of these, 13/39 (33.3\%) were using both forms of medicine concurrently to treat hepatitis.

The majority of herbal medicine users (129/143; 90.2\%) used their herbal therapies intermittently, and 91/143 (63.6\%) of users reported using their herbal treatments more than once a week. The profile and patterns of herbal medicine use are further summarized in supplementary table 2. (see supplementary table 2, Additional file 3).

Majority of the group patients concluded that it is not safe to use both kinds of therapies concurrently because they might interact thereby harming the body and leading to side effects such as skin rashes, blindness and organ damage such as kidney and liver damage as exemplified in the statement,

"Yes, it is not safe because one type of drug can reduce the strength of the other and the patient will end up not getting cured at all. It is better to first try one and then try the other." (Male, 50, FGD2).

\section{Communication from health workers about herbal medicine use}

Only $42 \%(60 / 143)$ of the patients using herbal medicine could recall any health-worker ever asking them about use of herbal medicine, with the majority reporting that they were discouraged from using it and advised to use conventional treatment instead. Only 40.6\% (58/143) of users reported ever starting a conversation with their health-worker about herbal therapies.

The main reasons given by patients for not talking to health-workers about herbal medicine included a fear of being discouraged from using herbal medicine (10.2\%), $37 \%$ of the patients did not find it necessary to talk about herbal medicine and another 10\% stated that they had never been asked about it.

This was confirmed in the group discussions which concluded that when health workers do talk about herbal medicine, they mainly discourage use without expounding on any effects that herbal medicines may have.

\section{Factors associated with herbal medicine use}

The following variables were significantly associated with herbal medicine use: education status, duration of illness, current diagnosis, belief that herbal treatment is completely safe and a belief that concurrent use of herbal and conventional treatment is safe as shown in Table 3.

The patients who had attained any form of education were less likely to use herbal medicine compared to those who were not educated however on adjusting for other factors, the education status was not found to be a significant factor in determining herbal medicine use.

Patients who had been diagnosed with hepatitis for a duration greater than 1 year; between 13 and 24 months (PRR ${ }^{2}$ 0.68,95\% CI 0.48-0.94, p 0.02); longer than 24 months (PRR 0.76, 95\% CI 0.57-0.99, p 0.04) before the study were also found to be less likely to use herbal therapies compared to those who had been diagnosed with hepatitis for a duration of less than 1 year before adjusting for other factors.

There was also a significant difference in the use of herbal medicine according to the type of hepatitis with which patients had been diagnosed. Patients who were diagnosed with hepatitis C (PRR 1.23, 95\% CI 1.14-1.33, $p<0.001$ ) and those diagnosed with other forms of hepatitis including alcoholic hepatitis and drug-induced hepatitis (PRR 1.23,95\% CI 1.14-1.33, p<0.001) were more likely to use herbal therapies compared to those who were diagnosed with hepatitis B before adjusting for other factors.

The perceived safety of herbal therapies was also shown to have a significant difference in use with the patients who believed that herbal medicines cause adverse effects (AEs) less likely to use herbal therapies compared to those who believed that herbal medicines are harmless (PRR 0.79,95\% CI 0.62-1.01, p0.06) before adjusting for other factors. Similarly, patients who believed that it is safe to use both herbal and conventional therapies concurrently (PRR 1.19, 95\% CI 1.02-1.39, p0.03) or who were not certain (PRR 1.36, 95\% CI 1.18-1.56, $p<$

\footnotetext{
${ }^{2}$ PRR- Prevalence rate ratio
} 
Table 3 Factors associated with the use of herbal medicine among patients diagnosed with hepatitis

\begin{tabular}{|c|c|c|c|c|c|}
\hline Factor & $\begin{array}{l}\text { Total } \\
N=310\end{array}$ & $\begin{array}{l}\text { Users } \\
n=143(\%)\end{array}$ & Non-users $n=167(\%)$ & Unadjusted PRR(95\%Cl) & $p$-value \\
\hline \multicolumn{6}{|l|}{ Age groups } \\
\hline $18-24$ & 77 & $21(14.7)$ & $56(33.5)$ & 1 & 1 \\
\hline $25-34$ & 100 & $51(35.7)$ & $49(29.3)$ & $1.09(0.87-1.37)$ & 0.45 \\
\hline $35-44$ & 74 & $31(21.7)$ & $43(25.8)$ & $0.97(0.74-1.27)$ & 0.84 \\
\hline $45-54$ & 47 & $32(22.4)$ & $15(9.0)$ & $1.14(0.91-1.44)$ & 0.26 \\
\hline$\geq 55$ & 12 & $8(5.6)$ & $4(2.4)$ & $1.02(0.71-1.49)$ & 0.88 \\
\hline \multicolumn{6}{|l|}{ Gender } \\
\hline Male & 171 & 77 (53.9) & $94(56.3)$ & 1 & 1 \\
\hline Female & 139 & $66(46.2)$ & $73(43.7)$ & $0.92(0.79-1.06)$ & 0.24 \\
\hline \multicolumn{6}{|l|}{ Residence } \\
\hline Rural & 59 & $33(23.1)$ & $26(15.6)$ & 1 & 1 \\
\hline Urban & 251 & $110(76.9)$ & $141(84.4)$ & $1.09(0.91-1.31)$ & 0.33 \\
\hline \multicolumn{6}{|l|}{ Education status } \\
\hline None & 4 & $3(2.1)$ & $1(0.6)$ & 1 & 1 \\
\hline Primary & 90 & $55(38.5)$ & $35(21.0)$ & $0.81(0.72-0.91)$ & $<0.001$ \\
\hline Secondary & 145 & $56(39.2)$ & $89(53.3)$ & $0.82(0.74-0.92)$ & 0.001 \\
\hline Post-secondary & 71 & $29(20.3)$ & $42(25.2)$ & $0.83(0.71-0.96)$ & 0.015 \\
\hline \multicolumn{6}{|l|}{ Current Diagnosis } \\
\hline Нер B & 289 & $130(90.9)$ & $159(95.2)$ & 1 & 1 \\
\hline Hep B \& C & 4 & $1(0.7)$ & $3(1.8)$ & $0.62(0.15-2.48)$ & 0.49 \\
\hline Hep C & 12 & $7(4.9)$ & $5(3.0)$ & $1.23(1.14-1.33)$ & $<0.001$ \\
\hline Others $^{a}$ & 5 & $5(3.5)$ & - & $1.23(1.14-1.33)$ & $<0.001$ \\
\hline \multicolumn{6}{|c|}{ Time since diagnosis } \\
\hline$<6$ months & 169 & $81(56.6)$ & $88(52.7)$ & 1 & 1 \\
\hline $6-12$ months & 67 & $31(21.7)$ & $36(21.6)$ & $0.96(0.82-1.11)$ & 0.56 \\
\hline 13-24 months & 34 & $14(9.8)$ & $20(12.0)$ & $0.68(0.48-0.94)$ & 0.02 \\
\hline$>24$ months & 40 & $17(12.0)$ & $23(13.8)$ & $0.76(0.57-0.99)$ & 0.04 \\
\hline \multicolumn{6}{|c|}{ Herbal medicine causing AEs ${ }^{b}$} \\
\hline No & 172 & $110(76.9)$ & $62(37.1)$ & 1 & 1 \\
\hline Yes & 76 & $23(16.1)$ & $53(31.7)$ & $0.79(0.62-1.01)$ & 0.06 \\
\hline Not sure & 62 & $10(7.0)$ & $52(31.1)$ & $1.06(0.87-1.30)$ & 0.53 \\
\hline \multicolumn{6}{|l|}{ Safe to use both } \\
\hline No & 192 & $53(37.1)$ & $139(83.2)$ & 1 & 1 \\
\hline Yes & 111 & $85(59.4)$ & $26(15.6)$ & $1.19(1.02-1.39)$ & 0.03 \\
\hline Not sure & 7 & $5(3.5)$ & $2(1.2)$ & $1.36(1.18-1.56)$ & $<0.001$ \\
\hline \multicolumn{6}{|c|}{ Higher cost of treatment } \\
\hline Conventional & 194 & $98(68.5)$ & $96(57.5)$ & 1 & 1 \\
\hline Herbal & 104 & $44(30.8)$ & $60(35.9)$ & $0.94(0.81-1.09)$ & 0.42 \\
\hline Not sure & 12 & $1(0.7)$ & $11(6.6)$ & $0.29(0.05-1.61)$ & 0.16 \\
\hline \multicolumn{6}{|c|}{ Communication from health workers } \\
\hline No & 212 & $83(58.0)$ & $129(77.3)$ & 1 & 1 \\
\hline Yes & 98 & $60(42.0)$ & $38(22.8)$ & $1.02(0.89-1.18)$ & 0.74 \\
\hline Total & 310 & $143(100 \%)$ & $167(100 \%)$ & & \\
\hline
\end{tabular}

${ }^{a}$ Others includes both alcohol-induced hepatitis and drug-induced hepatitis

${ }^{\mathrm{b}} \mathrm{AEs}$ - adverse effects 
0.001) were more likely to use herbal medicines compared to those who believed that it was unsafe to use both forms of therapies concurrently before adjustment.

No significant differences in prevalence of herbal medicine use was found according to age, sex, employment status, employment type, religion, area of residence, religion, accessibility, use of conventional treatment, cost of treatments and communication from health-workers. There was no significant difference in the prevalence odds of herbal medicine use between patients who reported that herbal medicine was more expensive compared to those who reported that conventional medicine was more expensive. Similarly, there was no significant difference in prevalence odds of herbal medicine use between patients who reported easier accessibility to either healthcare practitioners or herbal medicine practitioners.

After adjusting for demographic and clinical factors, patients who were more likely to use herbal medicine were those who were diagnosed with chronic hepatitis $\mathrm{C}$ infection (PRR 1.16; 95\% CI 1.07-1.31, $p=0.02$ ), compared to those with hepatitis $\mathrm{B}$ and those who believed that it was safe to concurrently use both herbal and conventional medicine (PRR 1.32; 95\% CI 1.10-1.59, $p=$ 0.003) compared to those who thought it was not safe to use both therapies.

Patients who had been diagnosed with any form of hepatitis between 1 to 2 years prior to the study (PRR 0.69 ; 95\%CI $0.49-0.98, p=0.03$ ) and those who had been diagnosed over 2 years' prior (PRR 0.77; 95\% CI 0.59 $0.98, p=0.05)$ were less likely to use herbal medicine. This is shown in Table 4.

\section{Discussion}

A high prevalence of herbal medicine use among viral and non-viral hepatitis patients in this sub-Saharan African setting was reported; similar to that observed in a similar adult population diagnosed with viral hepatitis in the US [8]. Usage was independent of sociodemographic factors and was not related to concurrent use of prescription medicine for hepatitis. Conventional and traditional medicine systems run parallel in Uganda, with patients switching from one form to another depending on which they believe is most suitable for a particular condition. Conventional medicine is expensive and relatively not accessible, compared to traditional forms of treatment. It is, therefore, not surprising that most patients resort to herbal therapies. Similar to findings of previous studies globally [24-30], our study found evidence to suggest that cultural attitudes and personal beliefs towards health and life strongly play a role in the motivation for and are more compatible with herbal medicine use which goes beyond sociodemographic determinants such as educational status, occupation and age.
Table 4 Results of multivariate analysis of factors associated with herbal medicine use among patients diagnosed with hepatitis

\begin{tabular}{llll}
\hline Factor & Categories & Adjusted PRR & $p$-value \\
\hline Socio-demographic & & & \\
Age groups & $18-24$ & 1 & 1 \\
& $25-34$ & $1.10(0.88-1.34)$ & 0.41 \\
& $35-44$ & $0.99(0.75-1.29)$ & 0.95 \\
& $45-54$ & $1.18(0.93-1.49)$ & 0.17 \\
& $\geq 55$ & $1.17(0.79-1.76)$ & 0.43 \\
Gender & Male & 1 & 1 \\
& Female & $0.94(0.82-1.06)$ & 0.31 \\
Education status & None & 1 & 1 \\
& Primary & $0.96(0.83-1.10)$ & 0.54 \\
& Secondary & $1.00(0.88-1.15)$ & 0.95 \\
& Post-secondary & $1.05(0.89-1.25)$ & 0.52
\end{tabular}

Clinical factors

Current Diagnosis

$\begin{array}{lll}\text { Hep B } & 1 & 1\end{array}$

Hep B \& C $\quad 0.52(0.13-2.08) \quad 0.36$

Hep C $\quad 1.16(1.07-1.31) \quad \mathbf{0 . 0 2}$

Others $\quad 1.04(0.92-1.17) \quad 0.52$

Time since diagnosis $\quad<6$ months $1 \quad 1$

6-12 months $0.96(0.84-1.10) \quad 0.52$

13-24 months $0.69(0.49-0.98) \quad \mathbf{0 . 0 3}$

$>24$ months $0.77(0.59-0.98) \quad \mathbf{0 . 0 5}$

On conventional treatment No

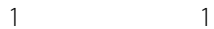

$\begin{array}{lll}\text { Yes } & 0.99(0.87-1.15) & 0.98\end{array}$

Safety profile

Safe to use both

$\begin{array}{lll}\text { No } & 1 & 1 \\ \text { Yes } & 1.23(1.05-1.43) & \mathbf{0 . 0 0 8} \\ \text { Not sure } & 1.32(1.10-1.59) & \mathbf{0 . 0 0 3}\end{array}$

Patients who were newly diagnosed up to 6 months were more likely to use herbal medicine, possibly because that they had not yet been well sensitized about the management of hepatitis and the potential dangers of using herbal medications in liver disease or that they had been using them prior to diagnosis. Namuddu et al. in 2011 also showed that newly diagnosed HIV patients on anti-retroviral therapy were more likely to use herbal therapies [21].

Cost was not been found to be a predictor of use in this study; consistent with other studies showing that cost only indirectly influences the use of alternative medicines; with accessibility and availability playing a bigger role $[26,28]$. Hepatitis $B$ infected patients on antiviral treatment in Uganda are treated at no cost; however, there are limited treatment options for hepatitis $\mathrm{C}$ with the available antiviral medication having prohibitive 
costs; likely playing a role in encouraging use of alternative therapies in this subset; similarly shown in a study by Ferruci et al. in 2010 [20].

Effective therapies for alcoholic-induced hepatitis and DILI are still limited, therefore influencing the use of herbal therapies which is also consistent with other findings [31].

The majority of herbal medicine users believed that herbal medicines were safe and concurrent use of both conventional and herbal medicine was perceived safe as well; congruent with other studies [28, 32]. Traditional use over many generations, without known negative effects, in addition to being natural, implies that herbal medicines are completely safe. However, herbal medicine has been known to cause herb-induced liver injury(HILI) $[18,33,34]$ when used alone or in combination with prescription medicines [35] and it is therefore imperative for health workers to educate patients on the potential dangers of herbal medicine use. This study did not explore whether liver injury might have occurred as a result of use of herbal medicine because despite different studies demonstrating evidence of herbal hepatotoxicity, there are challenges in establishing a diagnosis of HILI when the biochemical abnormalities of chronic liver disease already exist.

Most of our patients are not willing to disclose to health workers that they are using herbal medicine fearing discouragement and victimization, but also health-workers do not routinely talk to patients about this, which was consistent with studies in Australia and South Africa [36]. Given that adults seek the services of conventional health workers either after or concurrently with those of alternative medicine providers, health-workers have a unique opportunity to advise patients on the use of complementary and alternative medicine (CAM) and should do so without judgement and reproach.

A majority of patients rely on family members and friends for information about herbal medicine as well as mass media. Personal referral and recommendation for CAM has been previously identified as a powerful motivator for use [37, 38]. Extensive advertising of services and products by herbal practitioners can expose the population to unsubstantiated claims of disease management making this a pitfall as a source of knowledge for patients $[39,40]$. Herbal medicine messages in the mass media should be regulated to ensure population protection.

This study has a number of limitations which should be considered. Interpretation of our findings was based on self-report of herbal medicine use by the patients and prone to the effects of recall bias; which was mitigated by use of qualitative interviews to triangulate findings. Different understandings of the term 'herbal medicine' used in the interviews might have influenced the responses given but this influence was minimized by the interviewers elaborating on the questions and probing particularly for the use of local medicine and herbal extracts.

\section{Conclusion}

Our study provides insights into the use of herbal medicine by patients with viral and non-viral hepatitis. We showed that herbal medicine is used by a large proportion of patients, it is easily accessible and health care workers rarely discuss herbal medicine use during the process of providing care. Perceptions of safety of herbal medicines, hepatitis $\mathrm{C}$ diagnosis and recent diagnosis positively influence herbal medicine use.

To warrant patients' safety, dissemination of knowledge about herbal medicines both to health workers and as information for the general public can facilitate the conversation on potential risks and benefits thus promoting rational use. Health workers should regularly engage in conversations with their patients about their herbal medicine usage. Regulation of herbal medicine practitioners and products should be carried out and a streamlined policy on alternative healthcare in line with the population's cultural practices in Uganda should be developed. Findings suggest a need for clinical trials to determine the safety and efficacy of CAM products for the treatment of hepatitis $\mathrm{B}$ and $\mathrm{C}$ in comparison to conventional antiviral treatment.

\section{Supplementary information}

Supplementary information accompanies this paper at https://doi.org/10. 1186/s12906-020-02959-8

Additional file 1: This contains the survey questions administered to the study participants.

Additional file 2: Supplementary Table S1. Baseline characteristics of the Focus Group Discussions. This contains information on the baseline characteristics of the focus group discussions including age and gender.

Additional file 3: Supplementary Table S2. Profile of herbal medicine use among patients with hepatitis. This contains information on the profile of use of herbal medicine as collected from the participant interviews.

\section{Abbreviations}

CAM: Complementary and Alternative Medicine; DILI: Drug-induced liver inflammation; FGD: Focus group discussion; HBV: Hepatitis B virus; HCV: Hepatitis C virus; HILI: Herb-induced liver injury; HIV: Human Immunodeficiency Virus; NCDs: Non-Communicable Diseases; PRR: Prevalence rate ratio; STIs: Sexually Transmitted Infections

Acknowledgements

Not applicable.

Authors' contributions

SN wrote the concept, designed data collection tools, monitored data collection, wrote the statistical analysis plan, cleaned and analysed the data, and drafted and revised the paper. She is the guarantor. SK and JM monitored the concept writing, implementation of the project and writing of the manuscript. GA and JM contributed to writing the data analysis plan and contributed to the statistical analysis and interpretation of the data. PO and JM carried out critical revision and drafting of the manuscript. All authors approved the final version of the manuscript. 


\section{Funding}

The author(s) received no specific funding for this work.

\section{Availability of data and materials}

The datasets used and/or analysed during the current study are available from the corresponding author on reasonable request.

\section{Ethics approval and consent to participate}

This study was approved by the Institutional Review Boards of Makerere University School of Public Health and Mulago Hospital no. MHREC 1363. Written informed consent was obtained from all patients before participation in the study.

\section{Consent for publication}

Not applicable.

\section{Competing interests}

The authors declare that they have no competing interests.

\section{Author details}

${ }^{1}$ Infectious Disease Institute, College of Health Sciences, Makerere University, Kampala, Uganda. ${ }^{2}$ School of Public Health, College of Health Sciences, Makerere University, Kampala, Uganda.

Received: 13 September 2019 Accepted: 19 May 2020

Published online: 03 June 2020

\section{References}

1. Hepatitis B factsheet. In: World Health Organization:media centre[website]. July 2019 update. http:www.who.int/mediacentre/factsheets/fs204/en/. Accessed 7 Jan 2020

2. Global hepatitis report. Geneva: World Health Organization; 2017. Available at http://www.who.int/hepatitis/publications/global-hepatitis-report2017_ eng. Accessed July 2018.

3. Ringehan M, McKeating JA, Protzer U. Viral hepatitis and liver cancer. Phil Trans R Soc B. 2017;372(1732):20160274.

4. Bwogi J, Braka F, Makumbi I, et al. Hepatitis B infection is highly endemic in Uganda: findings from a national serosurvey. African Health Sciences. 2009; 9(2):98-108.

5. Opio CK, Seremba E, Ocama P, Lalitha R, Kagimu M, Lee WM. Diagnosis of alcohol misuse and alcoholic liver disease among patients in the medical emergency admission service of a large urban hospital in sub-Saharan Africa; a cross sectional study. Pan Afr Med J. 2013;15:23.

6. Langlois-Klassen D, Kipp W, Jhangri GS, Rubaale T. Use of traditional herbal medicine by AIDS patients in Kabarole District, western Uganda. Am J Trop Med Hyg. 2007;77(4):757-63.

7. Strader DB, Bacon BR, Lindsay KL, La Brecque DR, Morgan T, Wright EC, et al. Use of complementary and alternative medicine in patients with liver disease. Am J Gastroenterol. 2002;97(9):2391-7.

8. Stickel F, Schuppan D. Herbal medicine in the treatment of liver diseases. Dig Liver Dis. 2007;39(4):293-304

9. Levy C, Seeff LD, Lindor KD. Use of herbal supplements for chronic liver disease. Clin Gastroenterol Hepatol. 2004:2(11):947-56.

10. Siddiqui $U$, Weinshel EH, Bini EJ. Prevalence and predictors of herbal medication use in veterans with chronic hepatitis C. J Clin Gastroenterol. 2004;38(7):605-10.

11. White CP, Hirsch G, Patel S, Adams F, Peltekian KM. Complementary and alternative medicine use by patients chronically infected with hepatitis $C$ virus. Can J Gastroenterol. 2007:21(9):589-95.

12. Bean $P$. The use of alternative medicine in the treatment of hepatitis $C$. Am Clin Lab. 2002;21(4):19-21.

13. Chang J-M, Huang K-L. Complementary and alternative therapies in the treatment of chronic hepatitis B. Hepatitis B Ann. 2007;4(1):72-106.

14. Melchart D, Hager S, Albrecht S, Dai J, Weidenhammer W, Teschke R. Herbal traditional Chinese medicine and suspected liver injury: a prospective study. World J Hepatol. 2017:9(29):1141.

15. de Boer YS, Sherker AH. Herbal and Dietary Supplement-Induced Liver Injury. Clin Liver Dis. 2017;21(1):135-49.

16. Kessler RC, Davis RB, Foster DF, Van Rompay MI, Walters EE, Wilkey SA, et al. Long-term trends in the use of complementary and alternative medical therapies in the United States. Ann Intern Med. 2001;135(4):262-8.
17. Gupta NK, Lewis JH. Review article: the use of potentially hepatotoxic drugs in patients with liver disease. Aliment Pharmacol Ther. 2008;28(9):1021-41.

18. Auerbach BJ, Reynolds SJ, Lamorde M, Merry C, Kukunda-Byobona C, Ocama $P$, et al. Traditional herbal medicine use associated with liver fibrosis in rural Rakai, Uganda. PLoS One. 2012;7(11):e41737.

19. Quandt SA, Verhoef MJ, Arcury TA, Lewith GT, Steinsbekk A, Kristoffersen AE, et al. Development of an international questionnaire to measure use of complementary and alternative medicine (I-CAM-Q). J Altern Complement Med. 2009:15(4):331-9.

20. Ferrucci LM, Bell BP, Dhotre KB, Manos MM, Terrault NA, Zaman A, et al. Complementary and alternative medicine use in chronic liver disease patients. J Clin Gastroenterol. 2010;44(2):e40

21. Namuddu B, Kalyango JN, Karamagi C, Mudiope $\mathrm{P}$, Sumba S, Kalende H, et al. Prevalence and factors associated with traditional herbal medicine use among patients on highly active antiretroviral therapy in Uganda. BMC Public Health. 2011;11(1):855

22. World Health Organization. How to investigate the use of medicines by consumers / Anita Hardon, Catherine Hodgkin, and Daphne Fresle. World Health Organization. 2004. https://apps.who.int/iris/handle/10665/68840.

23. Zou G. A modified Poisson regression approach to prospective studies with binary data. Am J Epidemiol. 2004;159(7):702-6.

24. Lövgren M, Wilde-Larsson B, Hök J, Leveälahti H, Tishelman C. Push or pull? Relationships between lung cancer patients' perceptions of quality of care and use of complementary and alternative medicine. Eur J Oncol Nurs. 2011;15(4):311-7.

25. Sirois FM, Gick ML. An investigation of the health beliefs and motivations of complementary medicine clients. Soc Sci Med. 2002:55(6):1025-37.

26. Gyasi RM, Mensah CM, Osei-Wusu Adjei P, Agyemang S. Public perceptions of the role of traditional medicine in the health care delivery system in Ghana; 2011

27. McLaughlin D, Lui C-W, Adams J. Complementary and alternative medicine use among older Australian women-a qualitative analysis. BMC Complement Altern Med. 2012;12(1):34.

28. Gyasi RM, Asante F, Yeboah JY, Abass K, Mensah CM, Siaw LP. Pulled in or pushed out? Understanding the complexities of motivation for alternative therapies use in Ghana. Int J Qual Stud Health Well Being. 2016;11(1):29667.

29. Chandrakumar A, Xavier A, Xavier A, Manakkadiyil A, Reghu A, Thomas L. Implications of traditional medicine in the treatment of Hepatitis a in Kerala. J Tradit Complement Med. 2016:6(3):316-20.

30. Payyappallimana U. Role of traditional medicine in primary health care: An overview of the perspectives and challenges. Yokohama J Soc Sci. 2009;14:69-72.

31. Milosevic N, Milanovic M, Turkulov V, Stojanoska M, Abenavoli L, Milic N. May patients with alcohol liver disease benefit from herbal medicines? Rev Recent Clin Trials. 2016:11(3):227-37.

32. Holst $L$, Wright $D$, Haavik $S$, Nordeng $H$. The use and the user of herbal remedies during pregnancy. J Altern Complement Med. 2009;15(7):787-92.

33. Tilburt JC, Kaptchuk TJ. Herbal medicine research and global health: an ethical analysis. Bull World Health Organ. 2008;86:594-9.

34. Lui CW, Dower J, Donald M, Coll JR. Patterns and determinants of complementary and alternative medicine practitioner use among adults with diabetes in Queensland, Australia. Evid Based Complement Altern Med. 2012;2012:659419.

35. Agbabiaka TB, Wider B, Watson LK, Goodman C. Concurrent use of prescription drugs and herbal medicinal products in older adults: a systematic review. Drugs Aging. 2017;34(12):891-905.

36. Xue CC, Zhang AL, Lin V, Da Costa C, Story DF. Complementary and alternative medicine use in Australia: a national population-based survey. Altern Complement Med. 2007;13(6):643-50.

37. Bennett J, Brown CM. Use of herbal remedies by patients in a health maintenance organization. J Am Pharm Assoc. 2000;40(3):353-8.

38. Sirois FM, Purc-Stephenson RJ. Consumer decision factors for initial and long-term use of complementary and alternative medicine. Complement Health Pract Rev. 2008;13(1):3-19.

39. Peacock M, Badea M, Bruno F, Timotijevic L, Laccisaglia M, Hodgkins $C$, et al. Herbal supplements in the print media: communicating benefits and risks. BMC Complement Altern Med. 2019;19(1):196.

40. Munyaradzi M. Ethical quandaries in spiritual healing and herbal medicine: a critical analysis of the morality of traditional medicine advertising in southern African urban societies. Pan Afr Med J. 2011;10:6. https://doi.org/ 10.4314/pamj.v10i0.72212.

\section{Publisher's Note}

Springer Nature remains neutral with regard to jurisdictional claims in published maps and institutional affiliations. 